\title{
International Field Studies: Tools For Enhancing Cultural Literacy
}

Darlene Brannigan Smith, (E-mail: dsmith@loyola.edu), Loyola College, Maryland

Harsha Desai, (E-mail: hdesai@loyola.edu), Loyola College, Maryland

John Cotner, Loyola College, Maryland

Roger Kashlak, Loyola College, Maryland

\begin{abstract}
As part of Loyola College's Executive MBA Program, students participate in an international field study (IFS). This IFS provides participants with an experientially based learning opportunity to understand that there are leadership universals that every executive and manager needs to practice in order to be world-class at home and abroad; and to appreciate that valuing and leveraging cultural differences is key to success in a global environment. This paper presents our approach to enhancing the cultural competency and literacy of students enrolled in the program.
\end{abstract}

\section{THE NEED TO BUILD CULTURAL LITERACY AND COMPETENCY}

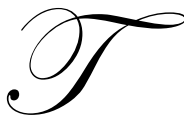

he new breed of international managers knows that "...in the SBU, TQM should reign, with products delivered JIT, where CFTs distribute while subject to MBO.... [And when everything else fails], “...we need to BPR.” (Trompenaars and Hampden-Turner 1998, pp. 11-13). Acronyms abound with universal applications and standardized definitions. Managers understand that SBU means "strategic business unit", TQM is "total quality management", JIT is "just in time", CFT means "customer first (focused) team", MBO is "management by objectives", and BPR is "business process reengineering." But how universal are these management techniques and solutions? Will they work just "as well" in Singapore, France or Japan as they seem to work in the United States or United Kingdom? Are these "management truths" applicable anywhere, under all circumstances?

Herein lies the challenge for managers operating in multinational environments. These individuals, having grown up and having had secondary and college education steeped in their home culture, are often employed by organizations owned and based out of another culture while working in yet another "third" country with a different language and culture. Exhibit one is a visual of this phenomenon. For example, a Chinese or Taiwanese employee is employed by McDonald's in Thailand. The employee, speaking Chinese (Mandarin, Cantonese, or even 'Shanghai-ese' or 'Taipei-ese') at home must be able to 'handle' the universal standardization practiced by the USbased McDonald's in a country (Thailand) that prides itself for its harmony with nature and which has not been under Western (or other foreign) rule for centuries. Similar cultural challenges are faced by a Canadian employee, working in a Japanese auto-parts plant in Malaysia! How does one reconcile that there are leadership universals that every executive and manager needs to practice in order to be world-class at home and abroad and yet appreciate that valuing and leveraging cultural differences is key to success in a global environment?

Rosen (2000) advocates that technology and management techniques alone will not give US businesses supremacy - we will also need to be culturally literate. Miller (1994) recommends that cultural competence ("to obtain those knowledges, skills, understandings and insights which enable one to understand the behaviors, values and approaches to life demonstrated by others different from themselves") and cultural literacy (an ever-changing and shifting body of information which a culture, or cultures, finds useful in defining itself through preservation efforts and historical documentation) must be imparted to managers if we are to be successful as world-class organizations. Mayo (2003) commenting on Trompenaars $(1993,1998)$ says that the challenge is much more than a 'show of respect' for other cultures - it requires managers to make a serious "effort to understand what drives a culture - the assumptions and expectations that bind people together collectively." 
In essence, culture provides the context for our individual behavior and, in large measure, defines our national character. For example, the way we value and structure time, how we define the employer-employee relationship, and our perspectives on and of various stakeholders and how we view them depend on our culture. Following Hofstede (1980, 1991), we define "culture" simply as "how things get done around here" and include in the definition shared values and beliefs, customs, habits, norms of behavior, traditions, tastes, perceptions of people themselves and of others and other such shared ways of how a people in a culture understand and interpret the world.

In the Seven Cultures of Capitalism, Hampden-Turner and Trompenaars (1993, pp. 11-13) suggest that different countries champion different value propositions for creating effective organizations. For example, Americans are considered Universalists (have you sampled a McDonald's hamburger in Moscow, Beijing, or Bangkok lately?) whereas the French are particularists. For the Japanese and Italians protecting a friend who is frequently late to the office with troubles at home comes ahead of supporting a general principle of "coming on time." (1993, p. 23). The authors identify seven pairs of unique tensions or propositions across cultures, including (1993, p. 11):

- $\quad$ universalism (call for universally applicable law and order) vs. particularism (allow for personal indulgence and idiosyncrasies),

- $\quad$ analyzing (demand for facts and attention purely on the bottom line) vs. integrating (viewing everything within the context),

- $\quad$ individualism (applaud individuals for singular performance) vs. communitarianism (organization, groups and community above else),

- $\quad$ inner-directed (self-starter) vs. outer-directed (approaching groupthink) orientation,

- $\quad$ time as sequence (time is money) vs. time as synchronization (all for one),

- $\quad$ achieved status (working hard to achieve) vs. ascribed status (status because of power), and

- $\quad$ equality (all get an even break) vs. hierarchy (some people are more important because of their hierarchical authority).

For some time we have been exploring how we can impart important dimensions of learning in a different culture where our Western, mostly American, theories and ways of doing things may not necessarily work. This is an especially important challenge for managers working in global environments - as manufacturing, markets, human resources, financial systems, backroom processing and even $R \& D$ become global/local. There is increased pressure on companies to standardize 'everything' and to create standard platforms that can be at a moment's notice adapted to local conditions as organizations reduce costs, improve quality worldwide, and serve diverse markets.

Our role as academics is to help develop global leaders at a time when international exposure and experience are vital to business success. In our MBA programs, the challenge is to develop a new set of attitudes, behaviors and competencies to help managers at all levels of business be more personally aware, socially skilled, economically enlightened and culturally wise. How do we help our students become more globally literate and to think with an international mindset while mobilizing people in culturally mindful way? This paper discusses the use of international field trips as an effective tool in helping students identify their prejudices, understand their own cultural lens, overcome their blind sports, and become comfortable in working across and around the many cultural barriers. If focuses on the tools used to help students build a model of cultural orientation and the in-country activities to enhance their cultural understanding, competency, and literacy.

\section{International Field Study}

An International Field Study (IFS) is a unique course that provides participants with an experientiallybased learning opportunity to develop a more global-centric approach to business. These relatively short one to two week international study programs are designed to give students a first-hand international perspective where they have an opportunity to study industries in global markets, visit specific companies operating in the industries they have studied, and learn more about the cultural, economic and financial infrastructure of various international 
markets. Participants develop a better understanding of the global business environment: its dimensions, trends and opportunities.

In recent years, Loyola College's classes have visited the emerging markets of Argentina, Chile, China, Czech Republic, Hungary, Netherlands, South Africa, Thailand and Vietnam. Our annual field studies afford our students the opportunity to travel to the far corners of the world to drop in on multinational and domestic companies to learn from their respective senior management teams. The site visits to companies are designed to give our executive participants an opportunity to understand the strategies pursued by these companies to compete in global markets - entry strategies, differentiation strategies, positioning postures for domestic and global competitors, and other functional tactics companies implement to survive and prosper. This international field study also affords an opportunity to improve one's ability to make better management decisions in a competitive global environment with a particular emphasis on emerging markets. We focus on applying the constraints and opportunities arising from diverse and changing international environmental factors (such as cultural distance, political risk, economic stability, legal complexities, and foreign exchange exposure) to actual managerial issues arising in conducting business overseas.

Yet, an international field study is more than site visits. Embedded in our MBA program, in general, and specifically in the International Field Study is a deep appreciation for what Rosen (2000) has defined as the four global literacies: personal, social, business and cultural. Personal literacy involves the understanding and valuing of oneself, developing strongly held principles and beliefs, insight and humility. Social literacy is about challenging and engaging others; the ability to build productive relationships and networks around the world. Business literacy teaches us the new tools and rules to mobilizing an organization in the twenty-first century. Cultural literacy is about understanding and leveraging cultural differences; working with diverse customers, employees and countries. The next section presents some of the activities we use to specifically develop the cultural literacy of our executive participants.

\section{Pre-Trip Activities: Building a Model of Cultural Orientation}

Prior to departing on an international field study, our EMBA students conduct extensive research to develop a better understanding of regions, countries, markets and cultures. They develop an in-depth study of the national culture by examining the impact of history, geography, economics, politics and culture on business success in the country. Exhibit Two profiles the levels of analysis undertaken in our international field studies.

The initial focus of study revolves around a traditional situational analysis, investigating macroenvironmental forces and country-specific issues, industry and market dynamics, and firms competing within these markets. Macro-environmental, or regional and country-level analysis is critical to identifying and assessing opportunities, threats and unique risks. Many of these risks are from the external, economic and political environment in the country. These influences include the relative stability of the country's foreign exchange, the cultural distance between home and host country, in-country political risk, and associated host government's restrictions on business operations. The next level of analysis is on the types of industries and organizations to be visited within the selected countries. Our goal is to develop site visits that allow our students to understand how firms navigate through the chaos of a global market to create value for customers. We have also found it advantageous to include visits with non-profit and 'charity' organizations along with for-profit businesses. These non-profit organizations provide a different and important perspective on the social, economic, and cultural aspects of the countries.

The final dimension of learning focuses on developing a cultural orientation of the countries / regions to be visiting on the international field study. The goal is to drive home the adage that while all business is global, all markets are local. We reinforce the premise that corporate survivability and prosperity increasingly depend on our ability to interact with and manage people of different cultures. Therefore, students learn about the cultures in the countries we visit and develop a model of cultural orientation that includes, but is not limited to, issues such as: 
।

\author{
- $\quad$ Values and beliefs \\ - $\quad$ Customs and traditions \\ - Habits and norms of behavior \\ - Cognitive styles, \\ - Negotiation strategies, \\ - Business practices and \\ - $\quad$ Standard business protocol.
}

The activities used to facilitate student learning are briefly discussed below.

\title{
| Guest speakers
}

Learning about culture from the collective wisdom of others is critical. Thus, whenever possible, we invite country-specific experts to share their real-life stories, experiences, and knowledge to compare and contrast cultural similarities and differences. These "experts" are quite diverse ranging from academic scholars, former American ex-pats to the region, foreign nationals or ex-pats from the respective country who are now residing in the United States, and Vice Presidents of Human Resources with expertise in cultural training and development. When possible due to our close proximity to Washington, DC, briefings by appropriate domestic and foreign Embassy personnel are provided.

\section{| Videos}

There are a number of excellent videos focusing on doing business in specific countries. WE frequently use the series developed by Big World entitled, "Doing Business In . . . (Argentina, Brazil, Chile, China, Vietnam, etc). Each film provides information on business customs in Chile, including the background of the country and its economy, business relationships, communicating, negotiating, and management. Each video lasts approximately 40 minutes and is accompanied with a comprehensive instructor's guide to facilitate class discussion.

\section{| Readings}

The list of references students can use to conduct their research is too extensive to list here. The following, however, is a list of some general references helpful in cultivating an inquisitive mindset and fostering student's | passion for being a global citizen.

- $\quad$ Friedman, Thomas (2000), The Lexus \& The Olive Tree, Anchor

- Hampden-Turner, Charles and Fons Trompenaars (1993), The Seven Cultures of Capitalism, CurrencyDoubleday

- $\quad$ Hofstede, Geert (1991), Culture's Consequences: International Differences in Work-Related Values. Sage Publications.

- $\quad$ Kanter, Rosebeth Moss (1995). World Class: Thriving Locally in the Global Economy, Simon \& Schuster.

- $\quad$ Morrison, Terri, Wayne A. Conway and George A. Borden (1997). Dun \& Bradstreet's Guide to Doing Business Around the World, Prentice-Hall

- $\quad$ Rosen, Robert (2000), Global Literacies, Simon and Schuster

- $\quad$ Trompennaars, Fons, and Hampden-Turner, Charles (1998). Riding the Waves of Culture: Understanding Diversity in Global Business, $2^{\text {nd }}$ ed, McGraw-Hill

Applying the knowledge learned is the key focus of the actual field study. The next section examines some of the in-country activities used to enhance cultural literacy. 


\section{IN-COUNTRY ACTIVITIES: ENHANCING CULTURAL LITERACY}

\section{Scavenger Hunts}

We have discovered that, in addition to making visits to various for- and not-for-profit organizations, taking our Executive MBA students on a journey of exploration through an semi-organized "scavenger hunt" provides a unique and might we say, quite fun-filled and wonderful opportunity to "understand and interpret" another culture. A scavenger hunt, organized in the country we visit, forces students to confront the day-to-day workings of a cityculture. The primary objectives of this activity are to:

- $\quad$ Achieve a fast acculturation into a city and what it has to offer

- $\quad$ Enjoy a quick lesson in navigating the streets of an unknown city.

- Interact with locals on a personal level.

A scavenger hunt carried out early in the study tour is a very effective and efficient way to immerse our students in the culture of the country. The scavenger hunts can last three to four hours in duration or may run over multiple days during the students' free time (i.e., late afternoon and evening hours). The specific scavenger hunts we designed for Beijing, China and Santiago, Chile are described in Exhibits 3 and 4. In general, students work in small teams (3-4 members each) and must stay together to accomplish the prescribed series of activities. Each team is asked to provide documentation (through photography) of all activities, interactions and transactions. In addition, students are required to use multiple modes of transportation (i.e., public bus, taxi, subway, etc.) to reach their destinations.

\section{| Cultivating Diversity and Debate Across Cultures}

One of the limitations of a short international field study is that it provides limited opportunity for learning and interaction with people in the local culture. Site visits and management presentations are relatively short in duration (2-3 hours) and often formal in their format. So, how does one encourage interaction, debate and learning? Loyola strives to affiliate with in-country MBA programs (for example, in Beijing, we work with the Beijing International MBA, BiMBA, program; in Santiago, we work with Universidad Alberto Hurtado) to design structured but personal learning activities between our respective students. For example, using a Harvard Business case as background, our students negotiated a market entry agreement with their counterparts at a Chinese university. After joint presentations of the "agreement," each Chinese-American negotiation team enjoyed a small-group dinner. A similar learning opportunity occurred between our students and Chilean MBA students. Students suggested that this intensive one-on-one activity yields phenomenal learning, intensive discussion and dialogue, laughter and levity, the formation of new friends, a significant reduction in stereotyping, and memories to last a life time.

\section{| A Focus on Corporate Social Consciousness and Responsibility}

Ultimately, global leaders are not successful unless they give something back to society. Not only do global leaders value the creation and distribution of wealth, but they are socially conscious and environmentally responsible. Thus, our cultural immersion experience is complemented with visits to charities and special presentations on the importance of corporate social responsibility. Visits to companies and organizations like Hogar de Cristo in Santiago de Chile provide our students a glimpse of how much good can be done for the poor and the infirm with a minimum of resources - a very different cultural experience indeed. Presentations by executives on how they express and operationalize social responsibility are vital to building student's global literacies. A presentation by a country's Minister of Health focusing on social safety net issues reinforces the importance of business to act responsibly with their newfound wealth and power! 


\section{Reflection and Integration}

Two of our final deliverables are the field study journal and the integrative, reflection paper. As our students travel to different countries and meet global leaders, they are asked to reflect about global literacy, global challenges, and the lessons they have learned in terms of their international mindset, leadership behaviors and what it requires to mobilize people in culturally mindful ways. A common theme found in these journals is how much our students have learned about themselves and have an opportunity to deeply reflect about their own arrogance, prejudice and ethnocentrism. While we have no empirical evidence, their reflections suggest that they have a better understanding of their personal strengths and flaws, are better able to understand what is best in our country and what are its strengths and weaknesses, and appreciate what they can learn from others around the world.

Have we developed globally literate leaders? Probably not. One program and one field study is insufficient for such a noble cause. We do suspect, however, that we have planted the seeds for our EMBA participants to become more globally and culturally literate and to understand what it takes to build a sustainable enterprise in the twenty-first century.

\section{REFERENCES}

1. $\quad$ Big World Video Series (1997). "Doing Business In ...” Publisher: Boulder, Colorado, Big World.

2. Hampden-Turner, Charles, and Trompennaars, Fons. (1993). The Seven Cultures of Capitalism, CurrencyDoubleday.

3. Hofstede, G. (1980). Culture's Consequences: International differences in work related values. Beverly Hills, CA: Sage.

4. Hofstede, G. (1991). Cultures and organizations: Software of the mind. London: McGraw-Hill.

5. Mayo, Andrew (2003) "Culture: The Mother of all Hurdles," Training Journal, (May), p. 36

6. Miller, E.K. (1994) "Diversity and its management: Training managers for cultural competence within the organization, Management Quarterly, (Summer), Vol. 35, No. 2, pp. 1723.

7. Rosen, Robert H. (2000) "In growing global economy, boost cultural literacy," Computerworld (April 24), Vol. 34, No. 17, p. 35

8. $\quad$ Rosen, Robert. (2000). Global Literacies: Lessons on business leadership and National Cultures, Simon \& Schuster.

9. Trompennaars, Fons, and Hampden-Turner, Charles (1998). Riding the Waves of Culture: Understanding Diversity in Global Business, ${ }^{\text {nd }}$ ed. McGraw-Hill

\section{EXHIBIT THREE CULTURAL INFUSION ACTIVITY: SCAVENGER HUNT IN CHINA}

\section{Description}

Designed after the theme of "Find Waldo" where students are asked to find the faculty stationed at predetermined locations around Beijing. Students are given sequential clues to find each of the four faculty. The clues came in different forms - poems, rhymes. Playing cards: initialized by the faculty at the station to keep track at being score. At each destination, a playing card is provided to each to "mark" their "place" in the race. An "Ace" is given to the first team, a " 2 " to the second team, and so forth. In addition, students collect designated items and provide answers to a questionnaire designed to measure their familiarity was some of the basic facts of China. Rankings in the scavenger hunt are based on a weighted measure of "timeliness" and "accuracy of responses".

Clue \#1: The first clue (in the form of a rhyme) leads the students to a Catholic church, adjacent to a Starbuck's. Two plaques inscribed in Chinese are located on the exterior wall of the Church. Students must provide the appropriate translation to the faculty stationed at the Starbucks in exchange for clues to the second destination. 
Clue \#2: Students are instructed to find a specific stall number in the Silk market and negotiate the lowest price possible on a specific product. Arrangements are made in advance with the vendor to provide the clues necessary to find the second faculty at a McDonalds adjacent to the Silk Market.

Clue \#3: The students are given clues to find the third faculty at a cyber café near Tiananmen Square. At the café, students access the Loyola College website for a clue to the fourth and final destination.

Clue \#4: The final stop is a Wine Bar, where refreshments are provided. After an appropriate "happy hour", the faculty lead the students in an informative and entertaining debriefing session where students share their insights.

\section{| Team Activities}

1. Take photos of one or more team members riding a bicycle and riding in a rickshaw.

2. Take a photo of your team in front of the US Embassy or the Ambassador's Residence.

3. Complete the attached questionnaire; accuracy is important!

4. Obtain the following items during your journey:

\section{- $\quad$ Bird kite}

- $\quad$ "Bill" or head of a duck

- $\quad$ Chinese tea

- $\quad$ Chinese candy / sweets

- $\quad$ Chinese herbal medicine (extra credit if you obtain an herb for men and one for women)

- $\quad$ Sample of Chinese poetry

\author{
- $\quad$ A small bottle of mau tai \\ - $\quad$ The little red book \\ - $\quad$ Chinese CD \\ - Chinese Newspaper (in English) - be \\ prepared to summarize front page news! \\ The "most unique" Chinese item you can \\ find!
}

\section{| Sample Cultural Infusion Questions}

1. What is the population of China - estimate after 2000? What percent is this number of the World population? What is the \% distribution of urban and rural population in China?

2. What is China's per capita GDP in US\$? What is the approximate literacy rate in China?

3. How long is the Great Wall of China?

4. What's a 'li'?

5. Who was Qin Shihuangdi? (Hint: Think Great Wall)

6. What is Meng Jiangnu famous for?

7. China' currency is called 'renminbi.' What else is it called?

8. What do the stars in China's national flag mean?

9. How many Special Administrative Regions does China have? Extra points: Name them.

10. There are eight main languages of China. Name three. Many extra points if you name all.

11. What is the approximate proportion of the ethnic Hans in China?

12. What is Xian famous for?

13. How is the auspicious wedding date selected in China?

14. Why are lotus seeds and two red dates used in tea ceremony in China?

\section{EXHIBIT FOUR CULTURAL INFUSION ACTIVITY: SCAVENGER HUNT IN CHILE}

\section{| Description}

Find all 3 faculty who will be stationed at predetermined locations around Santiago. Teams will be given sequential clues to these locations. When a team finds a faculty member, it will be given a playing card to mark its place in the race. An "Ace" will be given to the first team, a "2" to the second team and so forth. The first clue will be given to the teams with the initial instructions. 


\section{| Activities}

1. Obtain five of the following items during your journey:

- $\quad$ Item made of Lapiz Lazuli

- $\quad$ Item made of Alpaca

- $\quad$ Chilean CD

- $\quad$ Recipe for and/or list of 5 ingredients in a Pisco Sour

- $\quad$ Museum map

- $\quad$ Bus or metro schedule

2. Visit the following sites and provide proof of visit:

- $\quad$ La Moneda - Chilean Whitehouse

- Inside of Cal y Canta Metro station

- $\quad$ Pablo Naruda's house in Bella Vista

- $\quad$ Museum in Telefonica building

3. Make a purchase at the following locations (with proof):

- $\quad$ Mercado Central fruit/fish/vegetable (and purchase of one item)

- $\quad$ Purchase at Los Dominicos w/ proof

- $\quad$ An empanada from Tinita in Mercado Providencia

4. Take photos of the following:

- $\quad$ Photo of Ciudad Epressarial from La Piramide entrance to San Cristobal

- $\quad$ Photo of Estacion Mapocho

- $\quad$ Photo of Santiago city from Cerro Santa Lucia

\section{Sample Cultural Infusion Questions}

1. When did the Europeans first invade Chile? What was the name of the Spaniard who founded Santiago?

2. When did Chile claims its independence from Spain? Who became the first president of the Chilean republic?

3. Who is Pablo Neruda and what is he famous for? Arturo Pratt?

4. Which two religious orders have had a significant impact on the country's history and society? How?

5. $\quad$ Find the "Hamburger Index" and its ppp for the Chilean peso?

6. Who are the two most likely candidates for next year's Presidential race in Chile?

7. Chile is a republic consisting of how many regions and metropolitan areas?

8. What is the capital of Chile? Where is the seat of government located? Who heads it? Where is the national congress located?

9. Would Chileans classify their "democratic" government as a one-party system or a two-party system?

10. What is the population of Chile? Compare it to the population of Buenos Aires.

11. What is the name of the most recent Jesuit University in the world?

12. Identify the 5 most popular brands of Chilean wine. Rank them in order of your team's preference.

13. Name one product (in Spanish) made out of avocado. (Hint: It goes in a salad.)

14. Jumbo, the elephant, is a famous Disney character. What is Jumbo famous for in Santiago? 


\section{| Awards and Outcomes}

- $\quad$ Gift Certificate for Team Dinner to the team that finishes first AND completes all activities.

- Drinks at the bar for the team that provides the "most unique" Chilean item.

- Bottle of (Chilean, of course) wine for the team that negotiates the lowest price at the market.

NOTE

Full paper available from author. 